\title{
Quantificação do \\ Resíduo Sólido de ETA
}

\section{Rubia P. L. Camargo, Orlene S. Costa, Ítalo L. Fernandes \& Patrícia F. Góis}

Os resíduos sólidos vêm gerando várias discussões devidos os impactos que causam ao meio ambiente. As Estações de Tratamento de Água (ETA) geram alguns resíduos e dentre eles um resíduo sólido, o lodo formado nos decantadores. Poucas ETA se preocupam em tratar e dispor o lodo adequadamente, até mesmo pela dificuldade em se quantificar o resíduo. Este estudo teve como objetivo realizar a quantificação através de fórmulas pesquisadas por outros autores. Verificou-se que a quantidade de resíduo gerada em média é de $1306 \mathrm{~m}^{3}$ ao ano, confirmando a importância de tratar e dispor o resíduo ambientalmente correta.

Palavras-chave: lodo, decantadores, impacto.

Solid wastes have generated much discussion due to the impacts they cause to the environment. The water treatment plants (WTP) generate some of them waste and solid waste, the sludge formed in the decanter. Few WTP bother to treat and dispose of the sludge properly, even by the difficulty in quantifying the residue. This study aimed to perform the quantification using formulas studied by other authors. It was found that the amount of waste generated in average is $1306 \mathrm{~m}^{3}$ per year, confirming the importance of treating the waste disposal and environmentally friendly

Keywords: mud, decanters, impact. 


\section{Introdução}

A limitação dos recursos hídricos tem-se tornado cada dia mais intensa por alguns impactos: variações extremas do clima, crescimento populacional, e principalmente, por intervenção humana no meio ambiente, que afeta a qualidade da água e a capacidade natural de autodepuração dos corpos d'água ${ }^{1}$. Devido à necessidade de manutenção dos recursos hídricos para consumo, estudos estão sendo realizados para minimizar estes impactos, e evitar a temida escassez de água, podendo então atender a necessidade de água para consumo.

As administrações públicas dos centros urbanos estão visando cada dia mais a qualidade da água, mas em contrapartida, a quantidade de água doce disponível está menor, em função do descuido dos próprios sistemas de abastecimento e gestores municipais que não se preocupam com a degradação do meio ambiente. Hoje, tem-se observado projetos de reestruturação ambiental e de educação ambiental, que visam promover a conservação do meio físico e biótico do ser humano, mas que ainda não atingiram todas as cidades, sendo que, ainda se espera a dificuldade em obter, ou melhor, captar a quantidade e a qualidade de água ideal para se iniciar um trabalho de conscientização².

A grande maioria das ETA visam apenas a atingir a qualidade de água (potabilidade) para abastecimento dos centros urbanos e se esquecem dos resíduos que são jogados em cursos d'água sem nenhum controle e preocupação, contribuindo a contaminar e até mesmo reduzir a quantidade de água própria para consumo 3 . A ETA de Anápolis possui um tratamento de ciclo completo, gerando dois resíduos principais: a água de lavagem dos filtros (resíduo líquido) e o lodo gerado no processo de decantação, classificado pela NBR 10.004/2004 como resíduo sólido. A Resolução do CONAMA no 430/2011, determina os padrões mínimos para descarte de efluentes em corpos d'água, o que volta a reforçar a necessidade das ETA conhecerem o seu lodo (quantificação e caracterização) ${ }^{4,5}$. Com base nisso, este estudo visa à quantificação do resíduo sólido, o lodo dos decantadores, utilizando fórmulas empíricas.

\section{Referencial Teórico}

A quantidade de resíduos gerados em uma ETA varia com: o processo, os produtos químicos utilizados, a sazonalidade climática, a variação da água bruta e outros fatores. Em termos volumétricos o resíduo que possui maior volume é a água de lavagem, e em termos mássicos a maior quantidade de resíduo produzido é o lodo gerado na descarga de decantadores. Valores encontrados na literatura compravam este argumento: na água de lavagem são encontrados de 50 a $400 \mathrm{mg} . \mathrm{L}^{-1}$ de sólidos que corresponde de 2 a $5 \%$ do volume processado na estação, enquanto no lodo dos decantadores são encontrados de 500 a 30.000 mg.L ${ }^{1}$ de sólido, que representa de 0,1 a $0,3 \%$ do volume gerado na estação de tratamento ${ }^{6}$. Um estudo realizado por Kawamura (2000) mostrou que o lodo é muito mais concentrado que a água de lavagem dos filtros, o que justifica não realizar a mistura da água de lavagem como o lodo da descarga dos decantadores, pois poderia levar a uma diluição do lodo 7 .

O lodo gerado nos decantadores tende a compactarse no fundo, pois sua limpeza geralmente é realizada de 3 a 12 vezes ao ano, formando um adensado no decantador. A quantidade de lodo também é influenciada pela maneira como é realizada a limpeza, pois depende do procedimento realizado por cada operador, isto é, como ele utiliza a mangueira e o rodo para retirar o lodo, podendo utilizar mais ou menos água, gerando consequentemente mais ou menos lodo ${ }^{3}$. Dependendo do sistema de descarga dos decantadores, o volume é a concentração dos resíduos podem variar, ocasionando, lavagens mais frequentes dos sistemas de filtração, pois se a descarga dos decantadores ocorrer em espaços de tempo grande será arrastada para filtros um maior número de flocos. "As características desses resíduos dependem, principalmente, do método e da periodicidade das lavagens. Geralmente, a lavagem dos filtros é realizada somente com água, e consiste na aplicação de uma vazão ascensional”.

\section{FÓRMULAS EMPÍRICAS PARA QUANTIFICAR O LODO GERADO}

Vários pesquisadores desenvolveram fórmulas empíricas distintas para fazer a estimativa da produção de sólidos secos, sendo reproduzidas algumas na Tabela 1 para ETA que utilizam sais de alumínio ou ferro como coagulantes. Para facilitar, pode-se substituir o parâmetro “sólidos suspensos” por “turbidez”, visto que na maioria 
das vezes os dados de sólidos suspensos não estão disponíveis. Para isso, os autores sugerem a correção do valor da turbidez multiplicando-se por um fator que varia entre 1,0 a $2,0^{9}$.

A quantidade de logo gerada em ETA depende da natureza físico-química da água, da dose e tipo de coagulante e demais substâncias envolvidas na coagulação. Na estimativa de volume de lodo gerado em estações de tratamento de água, pode-se adotar como densidade de sólidos secos o valor médio de $1900 \mathrm{~kg} \cdot \mathrm{m}^{-3}{ }^{10}$.

\section{O IMPACTO AMBIENTAL PROVOCADO PELO DESPEJO DE DECANTADORES}

A toxicidade dos lodos gerados nas ETA depende de fatores como qualidade da água bruta, produtos químicos utilizados para o tratamento e outros como já descritos. Outros fatores que também influenciam nesta toxicidade são: a forma de remoção do lodo; tempo de retenção do lodo nos decantadores; características físicas, químicas e biológicas do curso d’água. Um dos produtos químico mais utilizado no tratamento é o sulfato de alumínio, sendo que o metal apresenta alta toxicidade em concentrações elevadas. Os lodos de ETA têm em sua composição concentrações elevadas de alumínio e esse material quando lançado em cursos d'água com baixa velocidade ou lagos pode sedimentar isolando a camada bentônica.

O lodo do decantador tem grande concentração de alumínio, podendo atingir até valores próximos de 4.000 mg. $\mathrm{L}^{-1}$. Quando dispostos em rios com baixa velocidade tende a causar problemas. Destacam-se alguns estudos citados por Cordeiro (1999) ${ }^{11}$ :

a) o alumínio em concentrações que variam de 0,05 a 2,5 mg.L-1 causou a morte de trutas (espécie de peixe) ou alterações funcionais como perda de equilíbrio, baixa percepção e desanimo generalizado;

b) a adição de alumínio em pequenos rios provocou alterações físicas e químicas na água, além de alterações na biota aquática;

c) para humanos que apresentam o sistema renal em bom funcionamento o alumínio não apresenta efeitos indesejados ou tóxicos, devido a rápida eliminação. Entretanto para o grupo de pessoas que tem problemas renais o alumínio pode concentrar em células cerebrais ou cardíacas, apresentando efeito nocivo;

d) quando a água utilizada por pacientes que faziam diálise possuísse concentração de alumínio superior a 0,08 mg.L-1 eles sofriam de demência;

e) suspeita-se que altas concentrações de alumínio estejam relacionadas ao mal de Alzheimer.

\section{Metodologia}

A ETA de Anápolis - Go trata a água bruta captada no Ribeirão Piancó, manancial localizado na zona rural de Anápolis . Após a água bruta ser transporta por uma adutora com cerca de $15 \mathrm{~km}$ de extensão, em linha reta, a água chega à estação de tratamento em uma câmara de entrada, onde recebe uma solução de cal para corrigir o pH. Em seguida, o sulfato de alumínio ferroso aquoso é dosado a água bruta para coagular e flocular, produzindo os flocos de lodo que são sedimentados no fundo dos decantadores. A água decantada segue para etapa de filtração, a fim de remover os flocos remanescentes. Depois, os filtros saturados são submetidos à operação de retro lavagem, gerando a água de lavagem.

Considerando que, a ETA possui quatro decantadores e que inexistem dados preliminares sobre a quantificação desses resíduos, optou-se por quantificar o lodo por método semi-empírico, utilizando fórmulas racionais, por não ser possível determinar a quantidade de lodo produzido no decantador pelo método volumétrico pelo fato de os decantadores não possuírem medidores de vazão na tubulação de descarga de fundo.

A quantidade de lodo gerada em um decantador foi estimada empregando-se cinco equações racionais. As fórmulas racionais são de autoria de Kawamura, Cornwell, WRC, AWWA e Richter, que empregam os seguintes parâmetros medidos na prática: produção de sólidos (P), em grama de matéria seca por metros cúbicos de água tratada; turbidez da água bruta (T), em uT; dosagem do coagulante (D), em mg. $\mathrm{L}^{-1}$; cor da água bruta (C), uC; concentração de outros aditivos (A), como carvão ativado em pó e polieletrólitos, em mg.L $\mathrm{L}^{-112}$.

A quantificação volumétrica da água de lavagem e do lodo do decantador em função do volume de água tratada, 
Tabela 1. Fórmulas empíricas para quantificação do lodo gerado em ETA²,10.

\begin{tabular}{|c|c|c|}
\hline Autor (Ano) & Fórmula Empírica & Legenda \\
\hline Kawamura (1991) & $P=(1,5 \times T+k x D)$ & $\begin{array}{l}\text { P: produção de sólidos (g de matéria seca / } \mathrm{m}^{3} \text { água tratada) } \\
\text { T: turbidez da água bruta (uT) } \\
\text { D: dosagem do coagulante (mg. } \mathrm{L}^{-1} \text { ) } \\
\mathrm{k}=0,23 \text { a } 0,26 \text { (sulfato de alumínio), } \mathrm{k}=0,54 \text { (sulfato férrico), } \mathrm{k}=0,66 \\
\text { (cloreto férrico anidro), } \mathrm{k}=0,40 \text { (cloreto férrico hidratado) }\end{array}$ \\
\hline $\begin{array}{l}\text { Water Research Center - } \\
\text { WRC (1979) }\end{array}$ & $\begin{array}{l}P=(1,2 \times T+0,07 \\
\times C+k \times D+A)\end{array}$ & $\begin{array}{l}\text { P: produção de sólidos (g de matéria seca / m³ de água tratada) } \\
\text { T: turbidez da água bruta (uT) } \\
\text { C: cor da água bruta (uC) } \\
\text { D: dosagem do coagulante (mg. } \mathrm{L}^{-1} \text { ) } \\
\text { k: coeficiente de precipitação, } \mathrm{k}=0,17 \text { (sulfato de alumínio líquido), k } \\
=0,39 \text { (cloreto férrico líquido) } \\
\text { A: outros aditivos, como carvão ativado pó e polieletrólitos(mg.L-1 }{ }^{-1} \text {. }\end{array}$ \\
\hline $\begin{array}{c}\text { American Water Works } \\
\text { Association - AWWA (1999) }\end{array}$ & $\mathrm{P}=3,5 \times \mathrm{T} \times 0,66$ & $\begin{array}{l}\text { P: produção de sólidos (g de matéria seca / m³ de água tratada) } \\
\text { T: turbidez da água bruta (uT) }\end{array}$ \\
\hline Cornwell (1987) & $\begin{aligned} P= & (0,44 \times \mathrm{DSA}+ \\
& 1,5 \times \mathrm{T}+\mathrm{A})\end{aligned}$ & $\begin{array}{l}\text { P: produção de sólidos (g de matéria seca / } \mathrm{m}^{3} \text { de água tratada) } \\
\text { DSA: dosagem de sulfato de alumínio (mg. } \mathrm{L}^{-1} \text { ) } \\
\text { T: turbidez da água bruta (uT) } \\
\text { A: outros aditivos, como carvão ativado pó e polieletrólitos (mg. } \mathrm{L}^{-1} \text { ). }\end{array}$ \\
\hline Richter (2001) & $\begin{aligned} S= & \left(0,2 \times C+k_{1} T+\right. \\
& \left.k_{2} D\right) / 1000\end{aligned}$ & $\begin{array}{l}\text { S: massa de sólidos secos precipitada em quilograma por metro cúbico } \\
\text { de água tratada; } \\
\text { C: cor da água bruta (uC) } \\
\text { T: turbidez da água bruta (uT) } \\
\text { D: dosagem de coagulantes (mg. } \mathrm{L}^{-1} \text { ) } \\
\mathrm{k}_{1}:=1,3, \mathrm{k}_{2}=0,26 \text {-oagulante sulfato de alumínio }\end{array}$ \\
\hline
\end{tabular}

foi realizada para verificar a porcentagem de resíduo gerado em relação a quantidade de água tratada e para verificar a relação entre os resíduos. Para a determinação do volume do lodo gerado foi feita uma média do lodo diário das cinco fórmulas racionais citadas acima. O cálculo foi realizado através da fórmula $V=m / \mu$, onde V é o volume do lodo gerado em metros cúbicos, m é a média da massa gerada de lodo diário e $\mu$ é a massa específica do lodo que é 2,65 gramas por centímetros cúbicos, segundo Cordeiro ${ }^{13}$.

\section{Resultados e Discussão}

Foi calculada a massa do lodo gerada, diária e mensalmente, para que se pudesse prever a quantidade de lodo gerada em cada mês, no período de agosto de 2010 a janeiro de 2011, e a massa acumulada. Estes cálculos e estimativas poderão servir de base para futuros estudos sobre tratamento e disposição do lodo da ETA de Anápolis. A Figura 1 apresenta a estimativa de massas de lodo produzidas por mês e as massas acumuladas no período de agosto/2010 a janeiro/2011 na ETA de Anápolis.
Observa-se que o mês de dezembro de 2010 foi o que mais produziu lodo, enquanto que o mês de agosto de 2010 foi o mês de menor geração de lodo. Os resultados mostram que os períodos de pouca chuva a água bruta se apresenta com menor quantidade de impurezas, ocasionando, por conseguinte, um menor consumo de produtos químicos durante o processo de tratamento, gerando menor quantidade de lodo para disposição final. Verifica-se que as estimativas das massas de lodo geradas em um período de seis meses, por diferentes equações racionais, apresentaram resultados distintos, com um valor mínimo de aproximadamente 372 toneladas (fórmula da WRC), um valor máximo cerca de 582 toneladas (fórmula da AWWA) e uma média em torno de 426 toneladas.

\section{QUANTIFICAÇÃO DOS RESÍDUOS GERADOS EM RELAÇÃO AO VOLUME DE ÁGUA TRATADA}

Segundo Castro (2000) a vazão média de resíduos gerados em uma ETA se encontra na dentro de 1 a $3 \%$ do volume tratado ${ }^{14}$. Na ETA de Anápolis os valores encontrados correspondem ao percentual dos resíduos 
Tabela 2. Quantificação volumétrica da água de lavagem e do lodo do decantador em função do volume de água tratada na ETA de Anápolis

\begin{tabular}{|c|c|c|c|c|c|}
\hline Tipo de Resíduo & $\begin{array}{c}\text { Volume diário de } \\
\text { resíduo produzido } \\
\left(\mathbf{m}^{3}\right)\end{array}$ & $\begin{array}{l}\text { Volume total/anual } \\
\qquad\left(\mathrm{m}^{3}\right)\end{array}$ & $\begin{array}{l}\text { Volume de água } \\
\text { tratada/anual }\left(\mathrm{m}^{3}\right)\end{array}$ & $\begin{array}{l}\text { Percentual do } \\
\text { resíduo (\%) }\end{array}$ & $\begin{array}{l}\text { Percentual dos resíduos } \\
\text { em relação ao volume } \\
\text { de água tratada }(\%)\end{array}$ \\
\hline Água de lavagem dos filtros & $1.200,00$ & $438.000,00$ & \multirow{2}{*}{$25.066 .192,50$} & 99,7 & 1,747 \\
\hline Lodo do decantador & 3,58 & 1305,7 & & 0,3 & 0,005 \\
\hline
\end{tabular}

gerados em relação ao volume de água tratada em torno de $1,75 \%$. O volume de água utilizada para lavagem de cada filtro varia de 120 a $170 \mathrm{~m}^{3}$, sendo um total de oito os filtros, totalizando um volume de $1.200 \mathrm{~m}^{3}$ diários (TABELA 2). O percentual do lodo gerado é de $0,3 \%$, estando dentro do valor estipulado em estudo realizado pela USEPA ${ }^{6}$.

\section{Conclusões}

A quantificação do lodo do decantador determinado por meio das equações empíricas de Kawamura, Cornwell, WRC, AWWA e Richter indicaram que os valores mínimo, médio e máximo a ser considerado na concepção de um projeto de tratamento do lodo da ETA Anápolis são de aproximadamente 372, 426 e 582 toneladas acumulado nos seis meses (agosto/2010 a janeiro/2011), respectivamente.

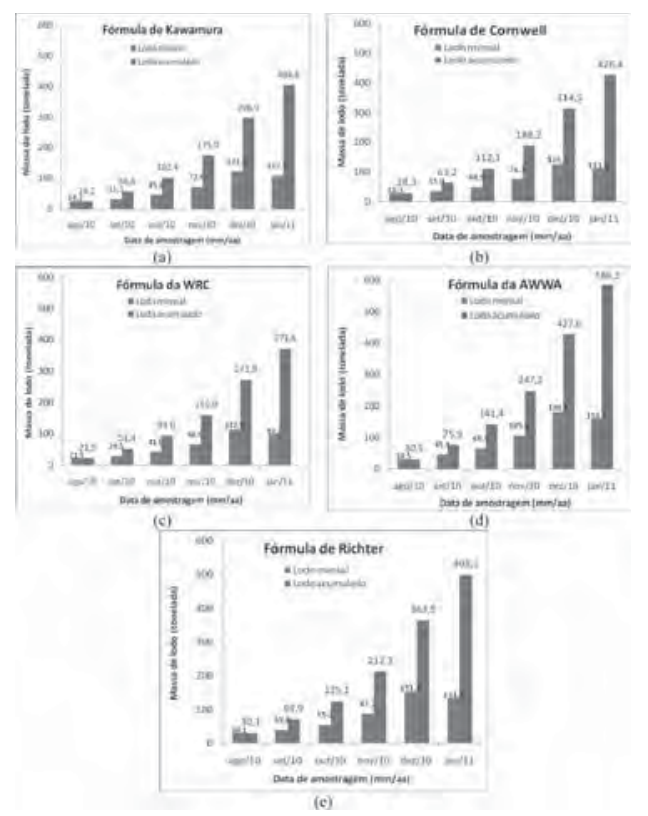

Figura 1. Massa de lodo produzida de ago./2010 a jan./2011, segundo as fórmulas racionais apresentadas por: (a) Kawamura, (b) Cornwell, (c) WRC, (d) AWWA e (e) Richter.
Deve ser instalado algum método de controle de vazão do lodo dos decantadores, como por exemplo, uma calha Parshall na canaleta de descarga de lodo para exata determinação das vazões mínimas, médias e máximas de lodo para fins de monitoramento rotineiro da estação.

\section{Referências Bibliográficas}

1. Santos, I. J.; Souza, M. A. A. Reúso de água: Uma análise da adequabilidade da utilização das águas residuárias tratadas no Distrito Federal. In: XXVII Congresso Interamericano de Engenharia Sanitária e Ambiental. ABES, 2001.

2. Reali, M. A. P. Noções gerais de tratamento disposição finais de lodos de estações de tratamento de água. Rio de Janeiro: ABES/ PROSAB, 1999.

3. Souza, F. G. C.; Cordeiro, J. S. Resíduos gerados em estação de tratamento de água com descargas diárias. In: $29^{\circ}$ Congreso Interamericano de Ingenieria Sanitaria y Ambiental, San Juan, ago, p.22-27, 2004.

4. Associação Brasileira de Normas Técnicas. NBR 10.004: resíduos sólidos - classificação. Rio de Janeiro, 2004.

5. Brasil: Conselho Nacional Do Meio Ambiente - Conama. Resolução nº 430. Ministério do Meio ambiente. Brasil, 2011, 8p.

6. USEPA - United States Environmental Protection Agency. Filter Backwash Recycling Rule. USEPA, E.U.A, 2002, 166p.

7. Kawamura, S. Integrated design and operation of water treatment facilities. Jonh Wiley \& Sons, Inc., New York, E.U.A. 2000, 691p.

8. Scalize, P.S. Caracterização e clarificação por sedimentação da água de lavagem de filtros rápidos de estações de tratamento de água que utilizam sulfato de alumínio como coagulante primário. (Dissertação de Mestrado) Escola de Engenharia de São Carlos, Universidade de São Paulo, São Carlos, São Paulo, 1997, 220p.

9. Ribeiro, F. L. M. Quantificação e caracterização química dos resíduos da ETA de Itabirito - MG. Ouro Preto, 2007. 133f. Dissertação de mestrado (Mestrado em Engenharia Ambiental) Universidade de Ouro Preto (UFOP). 
10. Richter, C. A. Tratamento de lodo de estação de tratamento de água. São Paulo: Editora Edgard Blücher Ltda, São Paulo, 2001.

11. Cordeiro, J. S. Importância do tratamento e disposição adequada dos lodos de ETAs. In: REALI, M. A. P. (Coord.) Noções gerais de tratamento e disposição final de lodos de estações de tratamento de água. Rio de Janeiro: ABES, 1999. cap. 1.

12. , D. A. Handbook of pratice water treatment plant waste management. American Water Works Association Resarch Foudation, Denver, 1 ed., Virginia, 1987, 431p.

13. Cordeiro, J. S. O problema dos lodos gerados em decantadores de estações de tratamento de água. (Tese de Doutorado) SHS - EESC / USP . São Carlos, São Paulo. 1993, 342p.
14. Castro C.; Castiglioni V. B. R.; Balla A.; Leite R. M. V. B. C.; Karam D.; Mello H. C.; Guedes L.C. A.; Farias J. R. B. Adubação. In: A cultura do girassol. Londrina - PR. Editora EMBRAPA, 1997. cap. 7 p 17 - 19.

Rubia P. L. Camargo*, Orlene S. Costa, Ítalo L. Fernandes \& Patrícia F. Góis

Ciências Exatas e Tecnológicas, Universidade Estadual de Goiás, CP 459, CEP 75.001-970, Anápolis/GO, Brasil.

*e-mail: ruluchetti@gmail.com 